\title{
Selection Versus Evolutionary Adaptation: Learning and Post-Entry Performance
}

by

John R. Baldwin* and Mohammed Rafiquzzaman**

No. 72

11F0019MPE No. 72

ISBN : $0-662-21724-1$

* Micro-Economic Analysis Division, Statistics Canada

and associate, Canadian Institute for Advanced Research, Economic Growth Program

Phone: (613) 951-8588

Email: BALDJOH@STATCAN.CA

** Micro-Economic Analysis Division, Statistics Canada

Phone: (613) 951-3758

$24 \mathrm{~F}$, R.H. Coats Building, Ottawa, K1A OT6

FAX: (613) 951-5643

April 1995

This paper has been accepted for publication by the International Journal of Industrial Organization

This paper represents the views of the authors and does not necessarily reflect the opinions of the Statistics Canada Bureau 
Aussi disponible en français 


\section{ABSTRACT}

This paper examines the maturation process of firms that enter an industry by constructing new plant and investigates the extent to which improvements in the performance of an entry cohort are the result of a selection process that culls out the most inefficient entrants or of a learning process that allows survivors to improve their performance relative to incumbent firms. Both selection and evolutionary learning are found to affect post-entry performance, but selection per se is a more important contributor to the overall growth of a cohort.

Journal of Economic Literature Classification: D21, D4, L1

Keywords: Entry, Learning, Performance, Selection 


\section{Introduction}

Most studies of entry have focused on measuring its importance at birth. ${ }^{1}$ These studies tend to find that entrants are relatively small and that they have high death rates. Previous Canadian work [e.g., Baldwin and Gorecki (1990a, 1990b, 1991)] examines the importance of entry by measuring it both in the short-run (instantaneous rates of entry) and the longer-run (cumulative rates of entry). While short-run entry rates are not large, the cumulative effect of entry over a 10-year period is substantial.

Instantaneous rates of entry capture the importance of entrants at birth; longer-run entry rates depend not only on the instantaneous rate but also on the success of an entry cohort as it matures. The challenges faced by new firms may differ at each stage. The birthing process requires new ideas, new products, new processes, and other innovative activity. The post-entry growth stage demands new organizational skills as firms master new techniques to handle increased product volume. Competitive threats from existing firms may also differ in the two stages. Most

entrants are small and offer little immediate threat to existing firms; however, as they grow, incumbents are more likely to devise reactive strategies to counter the new competitive threat that the emerging adolescent entrant presents.

Entry involves at least two different types of learning-one that comes from selection, one that is more evolutionary in nature. In the first case, entrants may physically have to be present to 
learn about their abilities to manage, to master technologies, to engender labour skills and to solve the myriad of other problems that are a prerequisite for success. Entrepreneurs differ in their capabilities and are unsure of their own capabilities before committing resources to a new business, that is, they do not have very precise information on what their costs will be relative to their competitors. Some firms will be better able to master skills that are required for success and will start off life with lower costs, a better product, and higher profits. These will be the firms that survive. Inferior entrants will be eliminated by natural selection. Jovanovic (1982) hypothesized that entry will be accompanied by a selection process that will weed out the more inefficient. Learning here is essentially accomplished by selection, that is, firms learn about their relative abilities at birth via the selection process. ${ }^{2}$

In the second case, the relative efficiency of entrants at the time of birth is not as important as is their ability to make progress in reducing the gap between incumbents and themselves after entry. Learning, in this case, is evolutionary. ${ }^{3}$ While skills may not be distributed equally upon entry, there is considerable opportunity to learn and to improve performance and it is this opportunity that leads to success. ${ }^{4}$ Evolutionary learning occurs in industries where exit is more or less random, or at least where it is not based on initial efficiency conditions and where substantial progress is made on the part of the surviving entrants in closing the initial gap that entrants have with incumbents. 
This paper examines the maturation process for entrants. It focuses on the post-entry performance of firms that enter an industry by constructing new plant (greenfield entrants). The second section describes the data used. The third section investigates post-entry performance by examining the size of entry and subsequent growth. It concentrates on describing changes in the relative size, wages, productivity, and profitability of this genus of entrant. ${ }^{5}$ The fourth section examines the characteristics that are related to successful growth by entrants and the degree to which the growth of a cohort confirms that the maturation process follows a pure selection process or an evolutionary model. In section 5, a model of entry is estimated that takes into account selection and evolutionary learning.

\section{Data}

Greenfield entrants provide the focus of this paper. Greenfield entry is defined to occur when a new firm enters an industry via the creation of a new plant. The data that are used for this study come from a longitudinal file constructed from the Canadian Census of Manufactures that tracks plants over the period 1970 to 1989 and links plants to firms.

Coming from the Canadian Census of Manufactures, the data are both comprehensive and precise (compared to non-official sources such as Dun and Bradstreet). The data are collected each year and, therefore, allow the annual performance of entrants to be tracked 
over time. While the data associated with each plant have been collected by a national statistical agency, the accuracy of the longitudinal identifiers attached to establishments that determine their birth and death status cannot be presumed simply because they come from an official source. Identifiers in these files may not have been created or maintained with longitudinal analysis in mind. Since it is the appearance of these identifiers that generates births, it is important that the statistical source not have reassigned identifiers to continuing plants and thereby have created false births and deaths. These problems are severe in some longitudinal files. ${ }^{6}$ Fortunately, statistics Canada has a well-defined procedure for deathing identifiers and used a rule that is relatively restrictive. ${ }^{7}$ In order to test the extent to which the rule was followed in practice, random sampling techniques were used to investigate the errors that were being made. They were found to be on the order of magnitude of less than .1\% (See Baldwin and Gorecki, 1990b).

\section{Post-entry performance}

In order to examine post-entry performance, a data base of greenfield entrants for the years 1970 to 1989 was created from the Canadian Census of Manufactures. Each cohort of entrants (consisting of the entrants who survived over time) was tracked from birth until the final year in the data base. The 1971 entry cohort could be tracked for 19 years. The 1988 cohort has only two 
years data attached to it. The performance of greenfield entrants is then represented by the average performance of all the cohorts in their first, second, third, and subsequent years. Because of the need to have a sufficient number of years over which post-entry performance is tracked, only entry cohorts commencing in the period 1971 to 1982 were used.

\subsection{Size}

Average annual greenfield-entry rates for the manufacturing sector over the period 1971-82 are presented in Table $1 .{ }^{8}$ On average, 6.7 percent of the establishments in any year belong to greenfield entrants that have just been birthed. In the year of their birth, entrants account for 1.75 percent of production. Table 1 also includes a gauge of success of these entrants. Greenfield entrants that survive to year ten are identified and their importance (in terms of share of production or share of number of establishments) in the first year of the cohort's existence is calculated (column 2). While 6.7 percent of establishments on average belong to greenfield entrants that have just been born, only 3.4 percent are greenfield entrants who will survive to age 10. The latter account for 1.21 percent of total production at birth. The ratio of the importance of these survivors to all entrants in the year of a cohort's birth is a measure of the greenfield survival rate. Only some 51 percent of a birth cohort will survive 10 years. ${ }^{9}$ In the birth year, these survivors account on average for 69 percent of the cohort's production. ${ }^{10}$ Thus, it is 
the smaller entrants that tend to die off early in life.

While greenfield firms are steadily weeded out as the age of an entry cohort increases, the maturation process yields larger firms that increase the importance of the group as a whole. As Table 1 further indicates, the share of plants accounted for by a greenfield cohort starts at 6.72 percent and has fallen to 3.10 percent by their ninth year of life (column 3 ). ${ }^{11}$ However, the surviving firms grow sufficiently to offset the output loss due to the high infant mortality rates. The average share of production accounted for by an entry cohort increases from 1.75 percent to 1.97 percent over the same period as the average size of the surviving firms increases.

\subsection{Productivity, wages and profitability}

Other changes occur in entrants as they mature-changes in their average wage paid, productivity and profitability. The post-entry course of these variables for a typical entry cohort is plotted in Figure 1. Remuneration is measured using the wage per production worker; productivity, using value-added per employee; ${ }^{12}$ and profitability, using the price-cost margin. ${ }^{13}$ The performance of all entrants is measured relative to all other firms in an industry using a weighted mean. For example, the size of the 1971 entry cohort in its fifth year (1975) in an industry is calculated relative to all plants in the same industry that continued over the period 1975-76. A weighted mean is used to calculate the characteristic for each industry ${ }^{14}$ and then the means of the 
relative characteristics calculated at the 4-digit industry level are averaged and reported in Figure $1 .{ }^{15}$

Entrants start with a disadvantage with regard to productivity, wages, and profitability; but the disadvantage varies by characteristic, as does the rate at which the gap with incumbents is closed. Entrants are less productive than the average incumbent. Labour productivity starts at about 60 percent of the average incumbent and rises to about 80 percent of it shortly after the tenth birthday of the entry cohort. ${ }^{16}$ These differences accord with the observation that small firms are less capital intensive than large firms. Greenfield entrants also lag behind incumbents in terms of average wage. The wage paid to production workers by entrants at birth is about 70 percent of the wage rate earned by workers in the average incumbent firm. After ten years, it has progressed to between 75 and 80 percent of the average incumbent wage rate.

It is noteworthy that the relative average wage paid by greenfield entrants starts at higher levels than the relative labour productivity. While entrants pay lower wages, this is offset by even lower labour productivity. That the productivity difference is wider than the wage difference implies that entrants initially experience a labour cost disadvantage even though they pay lower wages. However, this disadvantage gradually disappears over time. As a cohort matures, its relative wage rate increases more slowly than its relative labour productivity. By about the tenth year, relative labour productivity has caught up with average relative 
wage.

Although both the productivity and the wage rates of entrants lag considerably behind those of incumbents, this is not the case for profitability. At birth, the profitability of entrants is only 10 percent below that of incumbents. It moves up to the incumbent level by age 10. Entrants may be able to operate at the margin of an industry with a lower wage structure and a lower labour productivity, but they cannot continue to earn less than incumbents without being driven out of the industry.

In order to quantify the progress made by entrants, relative wages, productivity and profitability of each cohort were regressed on the age of the entry cohort. ${ }^{17}$ The estimated regression coefficients are reported in Table $2 .{ }^{18}$ Relative productivity grows at 2.5 percentage points per year, profitability at 1.1 percentage points per year, and the wage paid to production workers at only .7 percentage points per year. The relative productivity of entrants then grows almost three times as quickly as relative wage rates.

\section{Post-entry growth models}

Several models of entry have been proposed to explain the entry process. The most popular portrays entry as one of the basic equilibrating forces that overcomes disequilibrium profitability. In this paradigm, entry responds to above normal profitability but is deterred by barriers to entry. Others (Baldwin and Gorecki, 1987) have argued that entry is as much about replacing old firms 
that are producing outmoded products and using obsolete production processes as it has to do with the general profit-equilibration process.

It is clear that entry is a process that involves considerable mistakes. Entrants, like other firms are subject to the discipline of a competitive process that winnows out the incapable. While all firms have a positive failure rate, entrants have extremely high exit rates. This may mean that a percentage of entrants have false expectations of surviving. It suggests at a minimum that the selection process is particularly active in weeding out the most inefficient entrants.

\subsection{Learning by selection and evolutionary learning in the entrant population}

Entry involves two types of learning--learning by selection and evolutionary adaptation. Data on the post-entry performance of firms can be used to gauge the extent to which either or both learning processes exist and their relative importance. In order to examine the post-entry growth of new firms, the average performance of a cohort in years one, two, and three will be compared to its performance in years eight, nine, and ten. The ratio of the performance in its ninth year compared to its performance in its second year gives a measure of the growth experienced through the formative early years of life. Earlier work (Baldwin and Gorecki, 1991) demonstrates that exit rates are relatively high early in life and though the hazard rate has not yet reached an asymptote by 
year eight, it has begun to flatten out (see Baldwin, 1995). The early years in the life of an entry cohort are characterized by a high rate of infant mortality that leads to a major culling or winnowing out of the newly born. Measurement of the changes that take place in the entry cohort's productivity, wage rate paid, and profitability serve to clarify the nature of the evolutionary process and to discriminate between the two competing models of learning.

To calculate these measures, the population of entrants is divided into two groups-those that survive to early adolescence (age 10) and those that do not. The performance of the survivors during the first three years is then compared to that of the exiting entrants over the same time period. Natural selection occurs where surviving entrants perform better than exiting entrants. Industries where there is a difference between survivors and exiters and where survivors make little progress in improving their relative position are those where entrants as a group improve primarily because the most inefficient entrants are eliminated. These shall be called the natural selection industries. On the other hand, industries where there are no significant differences in the formative first three years between the entrants that survive and those that do not and where there is substantial improvement in the relative productivity or wages or profitability of surviving entrants are more appropriately entitled the evolutionary learning industries. Here it is a general improvement in entrants as a whole along with essentially random exit that 
generates progress in the cohort.

The relative importance of selection and learning on plantsize growth is presented in Table 3. For this table, relative plant size is calculated at the 4-digit level as an unweighted average ${ }^{19}$ and then averaged across industries. Entrants as a whole grow from 25 per cent of average incumbent size at birth to 48 per cent by early adolescence. Part of this comes from the growth of successful entrants, who start at 32 percent of the average and grow to the 48 percent level. Another part of the increase in average size comes from the fact that the exiting entrants are only 20 percent of the average, while survivors are over 50 percent larger. Thus, the disappearance of some entrants contributes to the increase in average plant size of the entry cohort.

The relative performance of the two classes of entrants with respect to labour productivity, wages, and profitability is also presented in Table 3 using a procedure similar to that employed for plant size. In each case, the successful entrants are superior to the unsuccessful entrants. They are 20 percent more productive, their profit margins are 28 percent higher, and their wage rate is 2 percent higher. As the successful entrants begin to make up a larger and larger share of the entry cohort, this difference in characteristics would naturally cause the cohort's performance as a whole to increase.

The selection process then contributes to the performance of entrants. What is more important, it is the major force at work in some instances. The relative productivity of the successful 
entrants does not improve over time. Thus, selection dominates learning at the early stage in an entry cohort's life, at least when it comes to increases in the labour productivity of a cohort.

For both average wages and profitability, improvements in incumbents do occur; but additional gains in the entry cohort also come from selection. Thus, selection is an important contributor to ongoing improvement in all cases.

\section{Cross-industry patterns of entry versus entry}

\section{growth}

While selection is clearly important, it varies in importance across industries. This section asks whether different patterns can be discerned and how these patterns relate to industry characteristics.

In order to do so, measures of the effect of entry both in the short run (instantaneous rates) and the growth of entry (the net change in an entry cohort's size) are used. Both are then related to measures of learning and selection.

\subsection{Variables used for analysis}

In this section, variables measuring entry, selection, learning, and the disadvantages of greenfield entrants are outlined. More precise variable definitions and summary statistics are provided in Table 4 . 


\subsubsection{Measures of the importance of entry}

Several measures of the importance of entry are used.

The first is the traditional instantaneous rate of greenfield entry (ENTRY)--a measure of birth weight. The second entry measure (ENTGR) represents the success that an entry cohort enjoys after birth. It is measured as the growth experienced during early childhood.

The success of an entry cohort will depend on two factors--the number of entrants that fall by the wayside and the growth in those who manage to survive. Two variables are used to capture these separate aspects of the growth process. The first is SURVIV--the proportion of an initial entry class who survive to early adolescence. The second is SURVGR--a measure of the growth of survivors between birth and early adolescence.

\subsubsection{Measures of evolutionary learning}

Learning variables are used to represent all those factors that enable new firms that start with a disadvantage relative to incumbents to reduce that disadvantage. These include such matters as the extent of knowledge diffusion, the ease with which new technology can be developed, and the ability to hire skilled production and management personnel.

Learning is represented in this study by the progress that the survivors in the entry cohort make over time relative to incumbents or continuing plants. This include variables that capture the progress in labour productivity (LEARNP), the wage rate (LEARNW), 
and size (LEARNS).$^{20}$

Larger values of these learning variables will occur in industries where the opportunities and the pressures for learning combine to provide for rapid improvements in entrants relative to the incumbent population. 


\subsubsection{Measures of the severity of selection}

The selection variables are designed to capture factors that are related to the intensity of the selection process. The selection process is less intense where only entrants with large disadvantages are removed from the race. The selection process is more intense when entrants with only a small disadvantage are eliminated.

Several measures of the disparity between survivors and exiting entrants are used to measure the extent to which the selection process winnows out the inefficient. These measures capture the productivity disparity (SELECP), the wage disparity (SELECW), and the size disparity (SELECS) between surviving and exiting entrants in the years just after birth when both are alive.

These measures are large when the selection process removes only those firms that are very much inferior to survivors. All else being equal, this will occur in industries where pressures arising from the selection process are not harsh. Severe selection will result in smaller values of this variable because smaller differences in performance will serve to eliminate the less efficient. Therefore, the severity of selection is inversely related to each of these variables.

\subsubsection{Measures of the disadvantage of entrants}

Measures of evolutionary learning and selection describe the post-entry path of entrants. In order to test whether the learning curve of an entry cohort is affected by its initial 
position, several measures of an entry cohort's starting point are calculated. These measure the disadvantage that a cohort faces at birth relative to incumbent firms. They capture the productivity disadvantage (DISADP), the wage disadvantage (DISADW), the cost disadvantage (DISADC), and the size disadvantage (DISADS) of entrants at birth. DISADC is labour productivity disadvantage divided by wage disadvantage. Since entrants suffer both a wage rate advantage and a productivity disadvantage, it is the net effect of the two that determines whether they suffer a labour cost advantage or disadvantage. These variables are inversely related to the disadvantage that entrants face.

It should be noted that the disadvantage of entrants is the net result of barriers and obstructions, on the one hand, that may cause entrants in some industries to experience greater disadvantages and, on the other hand, rewards that give firms the incentive to overcome these obstructions. For example, entry barriers might, on the one hand, be expected to lead to smaller size if entry at minimum-efficient scale is possible and, on the other hand, to lead to entry at larger average size since the costs of sub-optimal entry are higher. The nature of the relationship will be examined empirically by examining their correlations with industry characteristics. ${ }^{21}$

\subsection{The relationship between learning, selection and industry characteristics}


Several important questions can be addressed by examining the correlations of the learning, selection and disadvantage variables (Table 5) .

The first is whether learning and selection are related. Do they occur in the same industries, quite different industries, or in an unrelated fashion? Since the correlation between LEARNP and SELECP is negative and significant, in industries where the surviving cohort rapidly improves its position, the selection process is also more intense.

The second question is whether the entry cohort's starting point or initial position affects the learning process. Is the amount of learning exhibited by the surviving population related positively or negatively to the disadvantage that the entry cohort faces at birth? Since LEARNP and DISADP have a negative correlation that is significant, a greater productivity disadvantage leads to greater post-entry learning--as is manifested by growth in relative productivity. Productivity growth is also related to the labour cost disadvantage suffered at birth (LEARNP and DISADC have a negative correlation that is significant). Thus, where entrants suffer a greater labour-cost disadvantage, the pressure for improvement leads to more rapid learning by surviving entrants.

The third question is whether the selection pressures that weed out entrants on the basis of relative productivity are related to size differences. Since the correlation between SELECP and SELECS is positive and significant, these two forces are closely related. 
Finally, it should be noted that selection pressures are not related to the starting point of entrants--that is, they are not related to the size of the disadvantage of entrants at birth, either in terms of labour productivity, wages, or labour costs. SELECP and SELECS are not significantly correlated with DISADP, DISADS, or DISADC. Thus, the competitive pressures that cull the less efficient are not closely related to the type of industry characteristics that place entrants at an initial disadvantage.

This conclusion was further tested by correlating the learning, selection and disadvantage variables with the variables that are often used in an entry model. ${ }^{22}$ These variables are: profitability (PR), growth in profitability (PG), growth in sales (GS), concentration (CON), economies of scale (MES), research and development intensity (RD), advertising intensity $(A D)$ and demand variability (VMG). They are defined in Appendix A.

The disadvantage variables (DISADP, DISADW, DISADS) were negatively correlated with concentration (CON), advertising intensity ( $A D)$, economies of scale (MES), and research and development intensity (RD). The first two correlations, with concentration and advertising, were significantly different from zero. By way of contrast, the selection variables were positively correlated with all but the advertising variable. In particular, there is a positive and significant correlation between the selection variables and concentration. Industries which are more concentrated tend to be those where there are larger productivity, wage and size differences between the surviving entrants and 
exiters and where the selection process is less intense.

It is also the case that the learning variables are not closely related to the barrier variables. Learning then is a phenomenon that is not easily classified using the traditional taxonomy associated with the variables used in a standard entry model.

\subsection{The relationship between entry, learning and selection}

This section asks how the characteristics of the post-entry evolutionary process relate to the magnitude of entry taking place. It asks: What is the mechanism through which selection affects an entry cohort's success? Does the intensity of selection affect the rate of growth of a cohort or only the survival rate of a cohort? Is the evolutionary learning process related to survival or only to a cohort's growth prospects? Are industries where evolutionary learning takes place also those where there is more entry? How do the initial conditions affect the growth prospects of entrants? To answer these questions, the relationship between entry and learning or selection is examined using correlation and multivariate analysis.

Four different measures of entry are used-ENTGR, ENTRY, SURVIV, SURVGR. These variables were correlated with one another in order to examine whether the growth prospect of an entry cohort is related to its initial success (Table 6).

Instantaneous rates of entry (ENTRY) and the growth of the cohort (ENTGR) are negatively related and significant. The origin 
of these differences is evident when the two determinants of entry growth-the survival rate (SURVIV) and survivor growth (SURVGR)-are examined. There is a significant negative correlation between the survival rate (SURVIV) and the instantaneous entry rate (ENTRY). Where birth-year entry rates are higher, survival is lower and since survival is lower, growth in the overall cohort (ENTGR) is less. One interpretation of this finding is that a segment of entrants is overconfident and that the easier is entry, the greater is the importance of this fringe.

In contrast, survivor growth (SURVGR) is positively related to the instantaneous entry rate (ENTRY) and is significant. Industries in which more entry occurs are those where the births that reach adolescence are more likely to do better.

\subsubsection{Multivariate Analysis}

The learning and selection variables that have been devised to characterize the evolution of entrants represent underlying dynamic processes for which other measures like industry concentration are poor proxies (Baldwin and Gorecki, 1994). The selection variables are proxies for the intensity of the competitive process. The learning variables plot the trajectory of improvements that are made in the relative status of entrants.

This section uses multivariate analysis to test whether selection and evolutionary learning are associated with each of the entry measures when more traditional factors, like entry barriers, are also considered. 
Each of the measures of entry is regressed on the variables that are often used in an entry model-profitability (PR), growth in profitability (PG), growth in sales (GS), concentration (CON), economies of scale (MES), research and development intensity (RD), advertising intensity (AD) and demand variability (VMG). These variables are posited to affect both entry and entry growth. Just as barriers can be posited to deter entry (ENTRY), they may reduce the ability of small new entrants to grow to become medium-sized enterprises (ENTGR) because they act as mobility barriers (Caves and Porter, 1977).

The learning, selection and disadvantage variables are also included in the entry models. In order to represent the conditions that facilitate rapid improvement in the relative efficiency of entrants, the growth of relative labour productivity (LEARNP) and the growth of relative wages (LEARNW) are used. ${ }^{23}$ In order to capture the intensity of the competitive process, the relative wage of survivors to exiters (SELECW), and the size of survivors relative to exiters (SELECS) are employed. ${ }^{24}$ Larger values of these variables in each case are associated with less intense competitive pressures-because only the smallest and most inefficient are being eliminated. Finally, the cost disadvantage variable (DISADC) is used to represent impediments that are not captured by the standard entry-barrier variables. ${ }^{25}$ Larger values of this variable indicate that entrants more closely resemble incumbents and experience less of a labour-cost disadvantage. 
The multivariate results (Table 7) show that learning and selection play a separate role from the more traditional correlates.

Short-run entry (ENTRY) depends upon variables previously found to be related to entry-concentration (CON), growth (GS), market variability (VMG), and research and development (RD). ${ }^{26}$ Two of the newly constructed variables also have significant coefficients. First, the coefficient on LEARNP is positive. Thus, conditions that facilitate growth after birth have a beneficial effect on entry. ${ }^{27}$ An obvious determinant of entry is the ultimate success of entrants. Contemporaneous profit rates for the industry as a whole are one way to capture this effect. Measuring smaller firm profitability is another one. But neither have yielded very strong results for Canada in previous work (See Baldwin and Rafiquzzaman, 1993). The strong relationship between the instantaneous rate and subsequent growth suggests that the best evidence available for entrants on likely success is not profitability (where information that potential entrants can evaluate is likely to be sparse) but post-entry success based on output share-which is probably easier for potential entrants to evaluate.

Second, the cost disadvantage ratio (DISADC) also has a positive coefficient. A greater cost disadvantage (DISADC) at birth is associated with a lower initial market share for entrants.

The growth of entrants (ENTGR), like the instantaneous entry rate (ENTRY), also depends on the learning variable (LEARNP). But, 
thereafter, the determinants of post-entry growth are quite different than for instantaneous entry. First, growth of an entry cohort (ENTGR) is higher in concentrated industries. ${ }^{28}$ Second, initial cost disadvantage leads to more growth. Finally, the intensity of the selection process (SELECS) is a significant determinant of post-entry growth. These differences in the effect of the correlates help to explain why instantaneous and post-entry growth rates are negatively correlated.

The two constituents of entry growth--the survival rate (SURVIV) and the growth rate of survivors (SURVGR)--are positively related to either concentration or to economies of scale. SURVGR is positively related to the ability of survivors to learn (LEARNP has a positive coefficient that is significantly different from zero). The survival rate (SURVIV) is not significantly related to the learning process (LEARNP) but is to the intensity of the selection process (SELECS has a positive and significant coefficient). Higher survival rates occur where the selection process is less intense.

In summary, the multivariate results show how both selection and evolutionary learning are associated with entry. Certain characteristics of an industry that are represented here as providing opportunities for learning, and others that represent the intensity of competitive selection are both related to the entry process, but to different elements of it. Learning is positively related to the post-entry growth of survivors. Selection intensity affects the survival rate of entrants. Together they both affect the entry cohort's post-entry growth. While they are also related 
to traditional industry characteristics like concentration, the importance of scale economies and research and development activity, they are powerful enough to tell a separate story even when these variables are included in an entry model.

\section{Conclusion}

A number of conclusions emerge from this study. Instantaneous rates of entry can be better understood when the ultimate success of surviving entrants and the cost disadvantage of entrants are explicitly included in the model. Instantaneous entry rates are higher where the post-entry growth of survivors is greater. However, the process involves a complex negative feedback. Higher instantaneous entry leads to lower survival rates. In a sense, potential entrants overshoot and enter in larger numbers where high growth rates are expected. The selection process then serves to eliminate more firms in these situations. Despite this offsetting effect, the growth of the entry cohort as a whole (not just of survivors) is positively related to instantaneous entry.

The paper has also shown that both selection and evolutionary learning are related to post-entry performance. Selection intensity is more closely related to survival rates. Learning is related to survivor growth. Despite the difference in the effect of selection and evolutionary learning on the two components that determine the amount of post-entry growth, it is important to note that selection per se is an important contributor on average to overall growth in 
average productivity, wage rates, and plant size of a cohort.

Finally, initial disadvantage and growth are related in a way that suggest that evolutionary learning may be a function of necessity. Instantaneous entry is less where new firms enter with a labour cost disadvantage. On the other hand, where there is more of a cost disadvantage, there is greater post-entry learning and greater post-entry growth of survivors.

As usual, the results point to new issues that warrant further investigation. The determinants of the severity of the selection process need to be examined. The nature of the technological and innovation regime that are related to post-entry learning require investigation. Finally, the cross-industry pattern of selection and learning needs to be further explored. 


\section{Notes}

1. See Geroski and Schwalbach (1991). Exceptions can be found in Baldwin and Gorecki (1987) and Dunne, Roberts and Samuelson (1988) .

2. Ericson and Pakes (1992) refer to this as 'passive learning'.

3. This type of learning is classified as 'active learning' by Ericson and Pakes (1992).

4. Holmes and Schmitz (1990) note that individuals differ in their abilities to start a business and that the skills and entrepreneurial abilities required to start a business differ from the skills of running a business once it is established.

5. See Baldwin (1995) for an investigation of the effect of entry by merger.

6. For a more comprehensive discussion of problems with sources such as Dun and Bradstreet, see Baldwin and Gorecki (1990a) and Davis, Haltiwanger and Schuh (1994).

7. For a death to occur in the case of an ongoing establishment, the name, the ownership and the location of the plant must all change. For further details, see Baldwin (1995).

8. These estimates use all establishments in manufacturing except Head Offices.

9. The survival rate is the entry rate of survivors (using establishment counts) divided by the entry rate of all entrants (column 2 divided by column 1 in Table 1 ).

10. That is, the entry rate of survivors (using shipments) is 69\% of the entry rate of all entrants.

11. The average for performance at birth is calculated for years 1,2 and 3 . The average for adolescent performance is calculated for years 8, 9, and 10. Thus, adolescent performance is synonymous with performance in year 9 .

12. Production per worker was calculated by dividing value added for manufacturing operations by number of production workers. See Statistics Canada (1979).

13. Profitability is calculated as manufacturing value-added minus wages and salaries divided by manufacturing value-added.

14. The ratio for each industry is calculated as a weighted 
average. For example, for relative wages, it is the sum of wages divided by the sum of employees in entrants divided by the sum of wages for continuing plants divided by the sum of all employees in continuing plants. Using weighted averages rather than unweighted averages affects the level of the disadvantage but not the trajectory of the disadvantage (cf. Table 3).

15. Calculations of characteristics at the industry level were done for 145 of 167 4-digit manufacturing industries. In the remaining industries, greenfield entry was too small or too infrequent to allow meaningful measurements of the variables used here.

16. The reader is warned not to interpret this to mean that entrants cause productivity to fall. The contribution of entrants to gains in productivity occur because the productivity of firms that entrants replace is even less than that of entrants.

17. Regressions of the form: ln $y=a+b$ Age were estimated.

18. The regression is calculated using the average relative characteristic calculated from the entire manufacturing sector for each cohort--15 observations for each of the cohorts from 1971 to 1975, then 14 for the 1976 cohort, 13 for the 1975 cohort,..., 1 for the 1989 cohort. The total number of observations used in the regression was 180.

19. In contrast, Figure 1 used weighted averages of relative characteristics for each industry before calculating the simple arithmetic mean of the industry values. Two alternative methods were used here in order to show that the trajectory of post-entry success does not depend on whether weighted as opposed to unweighted averages are used.

20. A fourth variable, the change in profitability, was also employed but it turned out to have little or no relationship to any of the entry variables. Improvements in productivity and wages can be made slowly over time. Profits have to meet minimal standards quite quickly or firms exit.

21. Earlier work (Baldwin and Rafiquzzaman, 1993) found that the number of entrants to the Canadian manufacturing sector, but not their average size, was negatively related to concentration.

22. The entire correlation matrix is not presented here because of space restriction. It is available from the authors on request. 
23. LEARNS was excluded from the multivariate analysis because it was unrelated to all entry variables.

24. Because SELECP and SELECW are highly correlated (Table 5), only SELECW was used for the regression analysis.

25. Other disadvantage variables were not included in the multivariate analysis either because they were highly correlated with DISADC or were unrelated with any of the entry variables.

26. For other Canadian results, see Baldwin and Gorecki (1987), and Baldwin (1995).

27. Exclusion of this variable does not change the other coefficients in any significant fashion.

28. See also Audretsch and Mahmood (1992). 
$-29-$ 


\section{Appendix A: Description of variables used in entry model}

PR: The gross rate of return on capital defined as total activity value added less total activity value of wages and salaries, divided by the end of year gross capital stock for 1970 .

PG: The ratio of the largest firm (top half of employment) weighted profit rate in 1979 to 1970, where profit rate is defined as the weighted margins/sales ratio.

GS: The growth rate for real total activity value of shipments between 1970 and 1979 .

CoN: The 4-firm concentration ratio index.

MES: The market share (in terms of shipments) of the smallest enterprise required to account for 50 percent of industry employment.

RD: The ratio of research and development personnel to all wage and salary earners.

AD: The advertising-sales ratio.

VMG: The volatility of market growth, defined as the standard error of the residuals taken from a regression of the logarithm of shipments on time. 


\section{References}

Audretsch, D. B. and T. Mahmood, 1992, Firm selection and industry evolution: the post-entry performance of new firms, Discussion paper FS IV 92-7 (Research Unit, Market Processes and Corporate Development, Wissenshaftzentrum Berlin).

Baldwin, J. R. 1995, The dynamics of industrial competition: a north american perspective (Cambridge University Press, Cambridge).

Baldwin, J. R. and P. K. Gorecki, 1987, "Plant creation versus plant acquisition: the entry process in Canadian manufacturing," International Journal of Industrial Organization 5, 27-41.

Baldwin, J. R. and P. K. Gorecki, 1990a, Structural change and the adjustment process: perspectives on firm growth and worker turnover (Economic Council of Canada, Ottawa).

Baldwin, J. R. and P. K. Gorecki, 1990b, "Measuring firm entry and exit with panel data," in: A.C. Singh and P. Whitredge, eds., Analysis of data in time (Statistics Canada, Ottawa) 255-270.

Baldwin, J. R. and P. K. Gorecki, 1991, "Firm entry and exit in the Canadian manufacturing sector", Canadian Journal of Economics 24 , 300-323.

Baldwin, J.R. and P.K. Gorecki, 1994, "Concentration and mobility statistics in Canada's manufacturing sector", Journal of Industrial Economics, 62, 93-104.

Baldwin, J. R. and M. Rafiquzzaman, 1993, "Testing the robustness of entry barriers", in: J. Armstrong, N. Darcovich, and P. Lavallée, eds., Symposium 92: Design and analysis of longitudinal surveys (Statistics Canada, Ottawa).

Caves, R. E. and M. Porter, 1977, "From entry barriers to mobility barriers", Quarterly Journal of Economics 91, 241-261.

Davis, S. J., J. Haltiwanger and S. Schuh, 1994, Small business and job creation: Dissecting the myth and reassessing the facts, Working Paper No. 4492. National Bureau of Economic Research, Cambridge, Mass.

Dunne, T., M. Roberts, and L. Samuelson, 1988, "Patterns of firm entry and exit in U.S. manufacturing industries", Rand Journal of Economics 19, 495-515.

Ericson, R. and A. Pakes, 1992, An alternative theory of firm \& industry dynamics, Cowles Foundation Discussion Paper No. 1041 
(Yale University, New Haven, Connecticut). 
Geroski, P. A. and J. Schwalbach, 1991, Entry and market contestability: An international comparison (Basil Blackwell, Oxford).

Holmes, T.J. and J.A. Schmitz, Jr., 1990, "A theory of entrepreneurship and its application to the study of business transfers", Journal of Political Economy 98, 265-294.

Jovanovic, B., 1982, "Selection and the evolution of Industry", Econometrica 50, 649-670.

Statistics Canada, 1979, Concepts and definitions of the census of manufactures, Cat. No. 31-528 (Ministry of Industry, Trade and Commerce, Ottawa). 